DOI:10.18276/sip.2016.45/2-28

\title{
Marek Ogryzek*
}

Krystyna Kurowska**

Uniwersytet Warmińsko-Mazurski w Olsztynie

\section{OPRACOWANIE MAP ŚREDNICH CEN TRANSAKCYJNYCH GRUNTÓW ROLNYCH NIEZABUDOWANYCH ZBYWANYCH Z ZASOBU ANR OT OLSZTYN Z WYKORZYSTANIEM INTERPOLACJI METODA IDW ${ }^{1}$}

\begin{abstract}
Streszczenie
Do głównych zadań realizowanych przez Agencję Nieruchomości Rolnych należy poprawa struktury obszarowej gospodarstw, tworzenie warunków sprzyjających racjonalnemu wykorzystaniu potencjału produkcyjnego, a także proces restrukturyzacji gruntów Skarbu Państwa. Poznanie rynku nieruchomości powinno uwzględniać sytuację obecną oraz w miarę możliwości przyszłe tendencje. Istotną informacją usprawniającą zasady gospodarowania nieruchomościami rolnymi niezabudowanymi będącymi w zasobie ANR są informacje na temat cen nieruchomości oraz ich przestrzennego zróżnicowania. W ramach artykułu na potrzeby opracowania map średnich cen transakcyjnych gruntów rolnych niezabudowanych wykorzystano metodę interpolacji (IDW) średniej ważonej odległości. Wskazano również możliwości wykorzystania map w procesie gospodarowania nieruchomościami rolnymi Skarbu Państwa.
\end{abstract}

Słowa kluczowe: geostatystyka, interpolacja, zasób Agencji Nieruchomości Rolnych, nieruchomości rolne niezabudowane, cena transakcyjna

* Adres e-mail: marek.ogryzek@uwm.edu.pl.

** Adres e-mail: krystyna.kurowska@uwm.edu.pl.

1 Artykuł opracowano w ramach przedsięwzięcia ,Zastosowanie technologii GIS do gospodarowania zasobami Agencji Nieruchomości Rolnych na przykładzie ANR OT Olsztyn, Umowa Nr 02/ SFKiW/2015 


\section{Wstęp}

Agencja Nieruchomości Rolnych (ANR) jest następcą prawnym Agencji Własności Rolnej Skarbu Państwa. Jest instytucją powierniczą, której Skarb Państwa powierzył wykonywanie prawa własności i innych praw rzeczowych na jego rzecz $\mathrm{w}$ stosunku do mienia państwowego w rolnictwie. ANR wykonuje w imieniu własnym prawa i obowiązki związane z mieniem Skarbu Państwa powierzonym jej po zlikwidowanych państwowych przedsiębiorstwach gospodarki rolnej, w tym również prawa i obowiązki wynikające $\mathrm{z}$ decyzji administracyjnych. Realizuje również inne zadania określone odrębnymi przepisami, a w szczególności przepisami o kształtowaniu ustroju rolnego. ANR została wyposażona w uprawnienia, za pomocą których, działając w imieniu Państwa, sprawuje dyskretną kontrolę nad rynkiem nieruchomości rolnych, a w razie potrzeby może interweniować poprzez prawo państwowego pierwokupu. ANR może także podejmować decyzje dotyczące sposobu i trybu rozdysponowania nabytego w ten sposób nieruchomości (Ogryzek, Cymerman, Kurowska, Kryszk, 2014, s. 80). Dlatego bardzo ważne jest stworzenie narzędzia umożliwiającego rozpoznanie i dogłębną analizę rynku nieruchomości. Poznanie rynku lokalnego powinno uwzględniać sytuację obecną oraz w miarę możliwości przyszłe tendencje. Analiza rynku (w tym analiza cen nieruchomości rolnych) stanowi jedno z podstawowych narzędzi procesu podejmowania decyzji między innymi inwestycyjnych i administracyjnych czy prywatyzacji gruntów będących w zasobie Skarbu Państwa (Kurowska, Kryszk, Cymerman, 2014, s. 304). Przydatnym narzędziem mogą być mapy tematyczne, to jest mapy średnich cen transakcyjnych gruntów rolnych (Adamczyk i in., 2014, s. 38). Pojęcie to zostało zdefiniowane w rozporządzeniu Rady Ministrów z 3 października 2011 roku w sprawie rodzajów kartograficznych opracowań tematycznych i specjalnych, zgodnie z którym mapa ma przedstawiać zróżnicowanie średnich cen transakcyjnych gruntów przeznaczonych pod zabudowę oraz gruntów rolnych w skali całego kraju w powiązaniu z zasadniczym trójstopniowym podziałem terytorialnym państwa.

Według B. Prus (2010) i T. Budzyńskiego (2012) mapy wartości nieruchomości są niezbędne w gospodarowaniu nieruchomościami Skarbu Państwa. S. Źróbek z zespołami (Źróbek, Cellmer, Kuryj, 2005; Źróbek Cellmer, Janowski, Kuryj, 2006) i J. Bydłosz z zespołem (Bydłosz, Cichociński, Dębińska, 2010) mapy wartości gruntów postrzegają jako źródło informacji do podejmowania na rynku decyzji inwestycyjnych. R. Cellmer i współpracownicy (Cellmer, Kuryj, 2011; Cellmer, Senetra, Szczepańska, 2012; Cellmer, Bełej, Źróbek, Śubic-Kovać, 2014) zwracają uwagę na 
różnicę pomiędzy mapą cenności gruntu obszaru a mapą wartości gruntu. Mapy wartości nieruchomości zgodnie z ustawą (Ustawa, 1997) przedstawiają najczęściej wartość rynkową nieruchomości, którą definiuje się jako najbardziej prawdopodobną cenę nieruchomości możliwą do uzyskania na rynku, określaną na podstawie cen transakcyjnych z rynku lokalnego.

Przy wycenie nieruchomości rolnych niezabudowanych będących w zasobie ANR najczęściej są stosowane metody z podejścia porównawczego (metoda porównywania parami oraz metoda korygowania ceny średniej). Zarówno przy jednej, jak i przy drugiej metodzie uwzględniane są cechy nieruchomości mające istotny wpływ na wartość nieruchomości rolnej (Cymerman, Hopfer 2012). Natomiast przy tworzeniu mapy średniej ceny transakcyjnej możemy wizualizować rozkład przestrzenny cen i opracować na ich podstawie mapy prawdopodobieństwa wystąpienia według pewnych parametrów, czyli składową średniej ceny są jej cechy. Badaniami takimi zajmowali się K. Kurowska, H. Kryszk i R. Cymerman (2014, s. 295), którzy za ważny dla nieruchomości rolnych uznali parametr powierzchniowy. Nieruchomości podzielono na 3 grupy: do 5 ha, od 5 do 20 ha, powyżej 20 ha, dla których sporządzono mapy tematyczne - mapy średnich cen transakcyjnych. Stwierdzono, że najskuteczniejszym sposobem prezentacji danego zjawiska w przestrzeni, określania zmienności wartości przestrzennej, gęstości czy natężenia zjawisk geograficznych oraz relacji pomiędzy nimi są mapy tematyczne.

Innym podejściem są metody geostatystyczne tworzenia map wartości nieruchomości. Badaniami zajmowali się J. Bydłosz, P. Cichociński i E. Dębińska (2010), R. Cellmer ze współpracownikami (Cellmer i in., 2012; Cellmer i in., 2014) oraz P. Ciechociński (2011), który twierdzi, że interpolacja wartości nieruchomości daje najczęściej „niezadowalające rezultaty”. Jednak pojawiają się pewne problemy i wątpliwości przy wyznaczaniu obszarów cenności czy interpolacji różnych cen odnoszących się do tego samego miejsca w przestrzeni. Bardzo ważną kwestią w procesie sporządzania map tematycznych jest wybór właściwej metody i formy prezentacji kartograficznej. W związku z powyższym w niniejszym artykule podjęto próbę opracowania map średnich cen transakcyjnych gruntów rolnych niezabudowanych zbywanych z zasobu ANR OT Olsztyn z wykorzystaniem metod geostatystycznych. 


\section{Metodyka}

Na potrzeby artykułu zastosowano metodę monograficzną w odniesieniu do przeglądu literatury, przepisów prawnych, dokumentów regulujących zasady i tryb gospodarowania nieruchomościami pozostającymi w zasobie ANR oraz sporządzania map tematycznych i możliwości ich wykorzystania w procesie gospodarowania nieruchomościami.

Analizy przeprowadzono na przykładzie transakcji sprzedaży na obszarze działania ANR OT Olsztyn. Do opracowania map przyjęto transakcje, które miały miejsce w 2012 roku, w którym zaobserwowano wzmożoną sprzedaż gruntów rolnych z zasobu ANR. Na potrzeby analiz odrzucono transakcje poniżej 1 ha. Uwzględniono również formę zbycia: przetarg ograniczony, przetarg nieograniczony oraz sprzedaż na rzecz dzierżawcy w ramach pierwszeństwa w nabyciu. Mapy opracowano w programie ArcGIS z uwzględnieniem podziału terytorialnego na powiaty (mapa średnich transakcyjnych) oraz z wykorzystaniem interpolacji metodą (IDW) średniej ważonej odległości.

\section{Metody geostatystyczne}

Geostatystyka ma solidne podstawy teoretyczne (Krige 1951, 1952; Matheron 1962; 1965). Od początku lat dziewięćdziesiątych XX wieku geostatystyka jest stosowana głównie do opisu struktury przestrzennej i oszacowania wartości cech w miejscach niepomierzonych. Bierze ona pod uwagę przestrzenną dystrybucję cechy i bada zależność wartości cechy od odległości pomiędzy punktami, w których wartości te zostały pomierzone. Dlatego metody geostatystyczne zarówno pozwalają opisać statystycznie, jak i ułatwiają zinterpretowanie przestrzennej dystrybucji analizowanej cechy. Wyróżniamy metody geostatystyki, które umożliwiają analizę nie tylko danych ilościowych, ale również jakościowych. Zaletą niektórych jest brak wymogu co do normalności rozkładu danych analizowanej cechy. Geostatystyka dostarcza też unikalnych metod poprawienia dokładności szacowania jednej cechy z wykorzystaniem innej. Ponadto metody geostatystyczne pozwalają na precyzyjną ocenę niepewności wykonanych szacunków wartości cechy w miejscach, w których nie były one mierzone w terenie.

Podstawowymi narzędziami geostatystyki są: analiza wykresów rozrzutu, analiza statystycznych miar ciągłości przestrzennej zjawisk, metody krigingu 
(Tracz, 2010). Klasyczne metody statystyczne uwzględniają całą losowość w wyrażaniu błędu, podczas gdy struktura reprezentowana jest przez wyrażenie deterministyczne. Metody geostatystyczne pozwalają na traktowanie cen transakcyjnych jako zmiennej zregionalizowanej i tym samym przedstawienie losowości w warunkach fluktuacji, które nie stanowią błędów, ale są pewnymi cechami zjawiska charakteryzującymi się własną strukturą. Są one stosowane głównie do danych przestrzennie skorelowanych. Istota tych metod polega na przeprowadzeniu optymalnej interpolacji wartości średnich rozważanych parametrów i właściwym zinterpretowaniu struktury przestrzennej danych. Szczególną rolę odgrywa tu modelowanie struktury przestrzennej przedstawionej w postaci semiwariancji, a także estymacja (Cellmer, 2014).

Interpolacja jest analizą, która w bezpośredni sposób wykorzystuje pomiary terenowe oraz inne rodzaje próbkowania przestrzeni poprzez przewidywanie wartości w punktach nieobjętych pomiarami. Dokonuje się tego z założeniem, że punkty położone blisko siebie w przestrzeni mają bardziej zbliżone wartości niż znajdujące się w większej odległości. Procedura ta stosowana jest w następujących celach:

a) konwersji danych rastrowych $\mathrm{z}$ jednego poziomu rozdzielczości w inną; zazwyczaj oznacza to redukcję rozdzielczości do mniejszej;

b) wyznaczania konturów danych dla reprezentacji graficznej zawartości bazy danych;

c) przetworzenia punktów próbkowania w ciągły model pokrycia przestrzeni przez badane zjawisko;

d) konwersji jednej reprezentacji danych ciągłych w drugą, na przykład pomiędzy różnymi modelami reprezentacji danych wysokościowych, takimi jak TIN w GRID albo kontury warstwic w GRID (Adamczyk, Konieczny, 2010).

Wyniki interpolacji w bezpośredni sposób zależą od jakości próbkowania, a konkretnie od wyboru właściwej metody, gęstości próbkowania, różnorodności przestrzennej prób, dokładności pomiarów. Do grupy analiz opisowych prezentujących atrybuty danych przestrzennych zaliczane są proste metody interpolacji, do których należą:

- TIN (Triangular Irregular Network - nieregularna sieć trójkątów),

- IDW (Inverse Distance Weighted - metoda odwrotnych odległości).

W przypadku metody odwrotnych odległości wartość interpolowana obliczana jest na podstawie średniej ważonej z wartości zmierzonych w punktach, które zaliczą się w pobliżu punktu interpolacji, przy czym zazwyczaj w obliczeniach uwzględniania jest tylko pewna ograniczona liczba punktów pomiarowych. Głównym zało- 
żeniem jest przyjęcie, że wartości wag są odwrotnie proporcjonalne do potęg odległości między punktami interpolacji i punktem pomiarowym (stąd nazwa - metoda odwrotnych odległości). Oznacza to, że wpływ punktu pomiarowego maleje wraz z odległością. W metodzie IDW rola otaczających punkt estymowany danych w liczonej średniej jest zróżnicowana w zależności od odległości (Zawadzki, 2011):

gdzie:

$$
Z_{j}=\frac{\sum_{\mathrm{i}=1}^{\mathrm{n}} \frac{Z i}{h i j^{\beta}}}{\sum_{\mathrm{i}=1}^{\mathrm{n}} \frac{1}{h^{\beta}}},
$$

$\hat{Z} j$ - wartość cechy $Z$ estymowanej w punkcie $j$,

$Z i$-wartość cechy $Z$ zmierzona w punkcie $i$ (jednym z $n$ punktów danych w otoczeniu), $h i j$ - efektywna odległość między punktami $i$ i $j$, $b$ - wykładnik potęgowy - waga odległości.

Według J. Urbańskiego (2008) metoda odwrotnych odległości posiada wadę tworzenia sztucznych kulistych wzorów naokoło punktów pomiarowych. Opinia ta dotyczy jednak zjawisk przyrodniczych, a zastosowana metoda dla rynku nieruchomości i pojawianie się nazywanych przez Urbańskiego (2008) „takich tworów” może być jak najbardziej uzasadnione.

\section{Analiza cen transakcyjnych gruntów rolnych niezabudowanych}

Średnie ceny transakcyjne gruntów rolnych niezabudowanych stanowią bardzo ważną informację dla wielu podmiotów zarówno publicznych, jak i prywatnych. Szczególnie podmioty prywatne (głównie na potrzeby obrotu nieruchomościami) potrzebują informacji o ich wartości. Dla ANR analiza przestrzenna rozkładu wartości pozwala na racjonalne gospodarowanie mieniem Skarbu Państwa, które pozostało do rozdysponowania. Mapy średnich cen transakcyjnych powinny być opracowane na podstawie danych gromadzonych przez starostów w rejestrze cen i wartości nieruchomości, badań statystycznych oraz analiz i zestawień charakteryzujących rynek nieruchomości. Na potrzeby artykułu wykorzystano dane dotyczące transakcji sprzedaży z zasobu ANR OT Olsztyn w 2012 roku (rysunek 1). 
Rysunek 1. Mapa średnich cen transakcyjnych nieruchomości rolnych niezabudowanych uzyskanych przez ANR OT Olsztyn

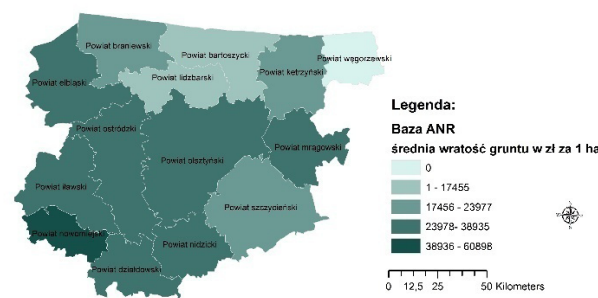

a) metoda klasycznej symbolizacji

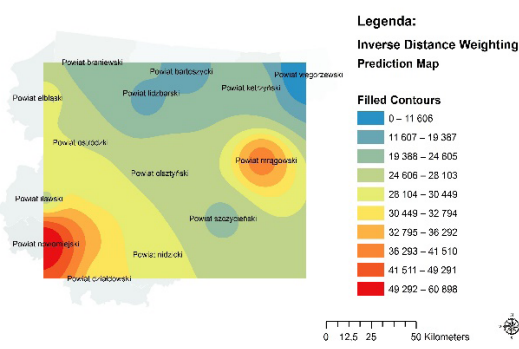

b) metoda IDW

Źródło: opracowanie własne na podstawie danych z ANR OT Olsztyn.

Na podstawie wcześniejszych badań stwierdzono, iż na uzyskiwane ceny transakcyjne duży wpływ miała forma zbycia (Kryszk, Kurowska, Ogryzek, 2014, s. 300). W związku z powyższym przedmiotowe mapy sporządzono w uwzględnieniem cen transakcyjnych uzyskiwanych w przetargu ograniczonym (rysunek 2), nieograniczonym (rysunek 3) i sprzedaży na rzecz dotychczasowych dzierżawców w ramach pierwszeństwa w nabyciu (rysunek 4).

Rysunek 2. Mapa średnich cen transakcyjnych nieruchomości rolnych niezabudowanych uzyskanych przez ANR OT Olsztyn w przetargu ograniczonym

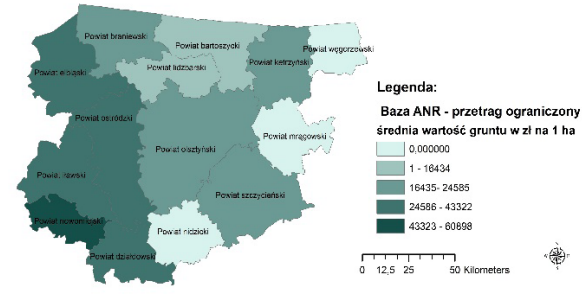

a) metoda klasycznej symbolizacji

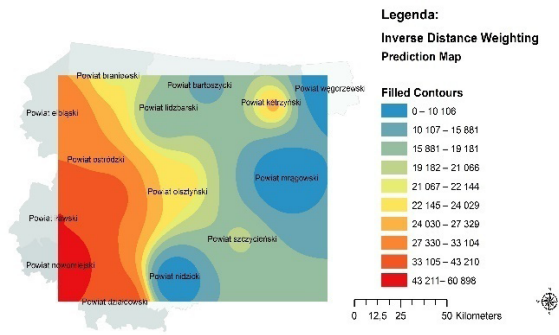

b) metoda IDW

Źródło: opracowanie własne na podstawie danych z ANR OT Olsztyn.

Na podstawie rysunku 2 w metodzie IDW możemy odnaleźć obszary cenowo „,zimne”, czyli poniżej średniej ceny transakcyjnej, i „ciepłe” - powyżej średniej ceny transakcyjnej. Powstałe oczka cenowe wskazują, iż na obszarach poniżej śred- 
niej ceny transakcyjnej występują ogniska sprzedaży średniej zlokalizowane przy dużych ośrodkach miejskich. Widoczny jest również podział na część zimną i ciepłą oraz przejściową średnich cen transakcyjnych. Takich analiz nie można przeprowadzić za pomocą metod klasycznych.

Rysunek 3. Mapa średnich cen transakcyjnych nieruchomości rolnych niezabudowanych uzyskanych przez ANR OT Olsztyn w przetargu nieograniczonym

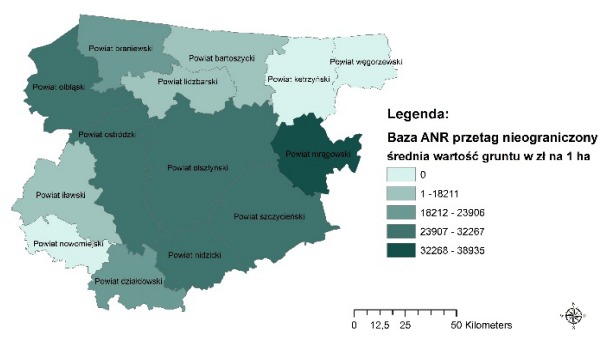

a) metoda klasycznej symbolizacji

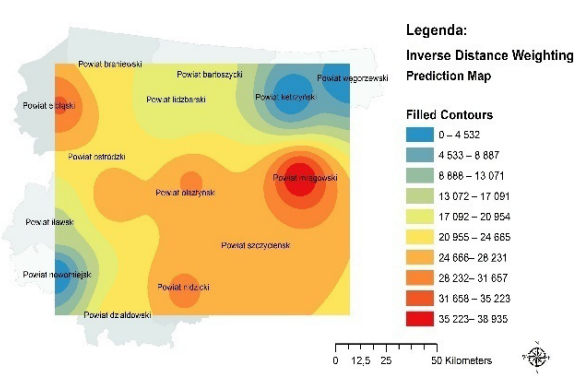

b) metoda IDW

Źródło: opracowanie własne na podstawie danych z ANR OT Olsztyn.

Analizując dane z rysunku 3, można stwierdzić, że obszary poniżej średniej ceny transakcyjnej znajdują się na obrzeżach zasobu ANR OT Olsztyn. Uzyskany rozkład cen transakcyjnych charakteryzuje się nierównomiernym rozłożeniem z niewielką strefą przejściową do obszarów o wyższej średniej cenie transakcyjnej.

Rysunek 4. Mapa średnich cen transakcyjnych nieruchomości rolnych niezabudowanych uzyskanych przez ANR OT Olsztyn na rzecz dotychczasowych dzierżawców w ramach pierwszeństwa w nabyciu

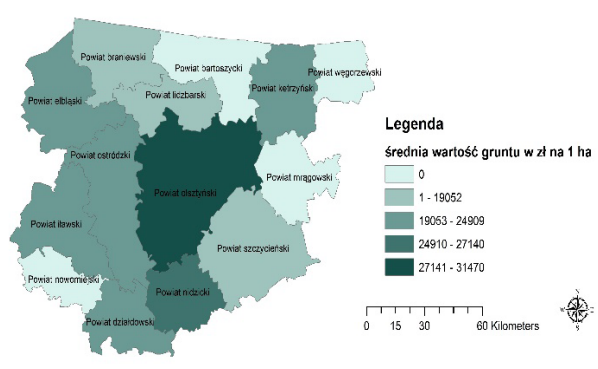

a) metoda klasycznej symbolizacji

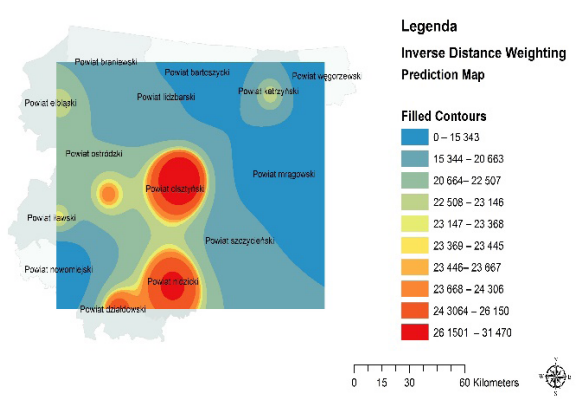

b) metoda IDW

Źródło: opracowanie własne na podstawie danych z ANR OT Olsztyn. 
Analizując dane z rysunku 4, zauważmy, że rozkład cenowy poniżej średniej ceny transakcyjnej przeważa na obszarze ANR przy sprzedaży na rzecz byłych dzierżawców z nielicznymi ogniskami cen powyżej średniej, które są zlokalizowane przy dużych ośrodkach miejskich.

Podsumowując, należy podkreślić, że zastosowanie metody IDW pozwala łatwiej modelować rozkład cen nieruchomości rolnych niezabudowanych z zasobu ANR OT Olsztyn. Analizowanie wyników uzyskanych metodą IDW jest łatwiejsze, gdyż ten sposób wizualizacji lepiej niż metody klasyczne odzwierciedla charakter i specyfikę rynku rolnego.

\section{Podsumowanie}

Mapa średnich cen transakcyjnych gruntów powinna obejmować obszar całej Polski, a dostęp do informacji przestrzennej, jakim jest średnia cena gruntów w gminie czy powiecie (niezależnie od typu transakcji - z zasobu ANR czy na rynku prywatnym), powinien być powszechny. Mapa średnich cen transakcyjnych gruntów rolnych powinna stanowić nowy element krajowej infrastruktury danych przestrzennych w Polsce.

Głównym celem badań było wskazanie narzędzi oraz metod do wizualizacji średnich cen transakcyjnych gruntów. Walidacji dokonano na podstawie cen transakcyjnych uzyskanych przez ANR OT Olsztyn w 2014 roku. Analiza rynku (w tym analiza cen transakcyjnych nieruchomości rolnych) stanowi jedno z podstawowych narzędzi procesu podejmowania decyzji między innymi inwestycyjnych i administracyjnych. Produkty tematyczne w postaci cyfrowych map średnich cen transakcyjnych gruntów stanowią przykład praktycznego zastosowania technologii GIS.

Na podstawie przeprowadzonych badań oraz literatury proponuje się włączenie metod geostatystycznych do opracowania map prawdopodobieństwa średnich cen transakcyjnych gruntów ANR. Głównym celem badań jest wskazanie narzędzi do wizualizacji wyników w ramach prowadzonych analiz przestrzennych. Zaproponowane narzędzia mogą być integralnym komponentem w racjonalnym gospodarowaniu zasobem Skarbu Państwa przez ANR OT Olsztyn. 


\section{Literatura}

Adamczyk, J., Konieczny, A. (2010). Rodzaje analiz przestrzennych. Warszawa: Centrum Informacyjne Lasów Państwowych.

Adamczyk, T., Begović, V., Bieda, A., Bielecka, E., Bugaj, P., Dawidowicz, A., Džunić I., Gajos, M., Jankowska, M., Kereković, D., Krukowska, K., Kryszk, H., Kurowska, K., Parzych, P., Rahmonov, O., Schrunk, I., Wojciak, E., Źróbek, R. (2014). Spatial Data in Widegeospace. Zagreb: Nacionalnaknjižnica.

Budzyński, T., (2012). Propozycje zastosowań mapy średnich cen transakcyjnych gruntów w gospodarce nieruchomościami. Studia i Materiały Towarzystwa Naukowego Nieruchomości, 20, 1, s. 135-144.

Bydłosz, J., Cichociński, P., Dębińska, E. (2009). Modelowanie baz danych o nieruchomościach. Archiwum Fotogrametrii, Kartografii i Teledetkcji, 19, 35-46.

Cellmer, R.(2014). The Possibilities and Limitations of Geostatistical Methods in Real Estate Market Analyses. Real Estate Management and Valuation, 22, 3, 54-62. DOI: 10.2478/ remav-2014-0027.

Cellmer, R., Bełej, M., Źróbek, S., Śubic-Kovać, M. (2014). Urban Land Value Maps a Methodological Approach. Geodetskivestnik, 58, 3, 535-551. DOI: 10.15292/geodetski-vestnik.2014.03.535-551.

Cellmer, R., Kuryj, J. (2011). Określanie stref o podobnej cenności gruntów z wykorzystaniem metod geostatystycznych. Studia i Materiaty Towarzystwa Naukowego Nieruchomości, 19, 3, 7-19.

Cellmer, R., Senetra, A., Szczepańska, A. (2012), Mapy wartości gruntów na terenach cennych pod względem przyrodniczym. Geomatics and Environmental Engineering, 6, 3, 15-24.

Cichociński, P. (2011). Comparison of Spatial Interpolation Methods for Real Estate Values. Journal of the Polish Real Estate Scientific Society, 19, 3, 120-132.

Cymerman, R., Hopfer, A. (2012). System, zasady, procedury wyceny nieruchomości. Warszawa: Polska Federacja Stowarzyszeń Rzeczoznawców Majątkowych.

Krige, D.G. (1951). A Statistical Approach to Some Basic Mine Valuation Problems on the Witwatersrand. Journal of the Chemical, Metallurgical and Mining Society of South Africa, December, 119-139.

Krige, D.G. (1952). A Statistical Analysis of Some of the Borehole Values in the Orange Free State Goldfield. Journal of the Chemical, Metallurgical and Mining Society of South Africa, Septemeber, 47-64.

Kryszk, H., Kurowska, K., Ogryzek, M. (2014). Analiza cen transakcyjnych nieruchomości gruntowych niezabudowanych będących w zasobie ANR OT Olsztyn. Studia i Prace Wydziału Nauk Ekonomicznych i Zarządzania, 36, 1, 291-302.

Kurowska, K., Kryszk, H., Cymerman, R. (2014). Identyfikacja czynników wpływających na kształtowanie się cen transakcyjnych nieruchomości rolnych będących w zasobie ANR OT Olsztyn. Studia i Prace Wydziału Nauk Ekonomicznych i Zarzadzania, 36, 1, 303-316.

Matheron, G. (1962). Traité de Géostatistiqueappliquée, tome 1 (1962), tome 2 (1963). Paris: Editions Technip. 
Matheron, G. (1965). Les variables régionaliséesetleur estimation. Paris: Masson.

Ogryzek, M., Cymerman, R., Kurowska, K., Kryszk, H. (2014). Analiza zmian struktury własnościowej zorganizowanych gospodarstw rolnych z zasobów ANR OT Olsztyn.

W: J. Koniczna, A. Trysuła (red.), Zrównoważony i wielofunkcyjny rozwój obszarów wiejskich (s. 77-75). Olsztyn: Partner Poligrafia.

Prus, B. (2010). Mapy wartości gruntów, jako czynnik wspomagający gospodarowanie terenami w gminie. Infrastruktura i Ekologia Terenów Wiejskich, 12, 169-177.

Rozporządzenie Rady Ministrów z 3.10.2011 w sprawie rodzajów kartograficznych opracowań tematycznych i specjalnych. Dz.U. nr 222, poz. 1328.

Tracz, W. (2010). Geostatyka w leśnym SIP. Warszawa: Centrum Informacyjne Lasów Państwowych. Urbański, J. (2008). GIS w badaniach przyrodniczych. Gdańsk: Wyd. UG.

Ustawa z dnia 21.08.1997 o gospodarce nieruchomościami. Dz.U. 2015, poz. 782, z późn. zm. Zawadzki, J. (2011). Metody geostatystyczne dla kierunków przyrodniczych i technicznych. Warszawa: Oficyna Wydawnicza Politechniki Warszawskiej.

Źróbek, S., Cellmer, R., Janowski, A., Kuryj, J. (2006). Propozycja technologii opracowania mapy wartości dla miasta Olsztyna. Przegląd Geodezyjny, 10, 3-9.

Źróbek, S., Cellmer, R., Kuryj, J. (2005). Land Value Map as a Source of Information about Local Real Estate Market. Geodezja, 11 (1/1), 63-73.

\title{
PREPARATION OF AVERAGE TRANSACTION PRICES MAPS FOR UNDEVELEPED AGRICULTURAL LANDS FROM AGRICULTURAL REAL ESTATE AGENCY RESOURCES IN OLSZTYN USING INTERPOLATION IDW METHOD
}

\begin{abstract}
The main tasks carried out by Agricultural Real Estate Agency (AREA) are improvement of farm structure, making favourable conditions for rational utilizationof production potential and taking care of restructuring process ofthe real estateTreasury. Knowledge about real estate market should include current situation and, as far as possible, future tendencies. Relevant data, that helps to improve undeveloped agricultural lands management from AREA resources, are the information about estate prices and their spatial differentiation. This paper presents preparation of average transaction prices maps for undeveloped agricultural land using the weighted average distance interpolation IDW method. The capabilities of using maps in Treasury agricultural property management were also indicated.
\end{abstract}

Translated by Marek Ogryzek

Keywords: geostatistics, interpolation, Agricultural Real Estate Agency resources, transaction price, agricultural land undeveloped

JEL Codes: C1, R3, Q11, Q15 
